\title{
Relative Humidity over the West Florida Continental Shelf
}

\author{
J. I. Virmani AND R. H. Weisberg \\ College of Marine Science, University of South Florida, St. Petersburg, Florida
}

(Manuscript received 10 May 2004, in final form 22 October 2004)

\begin{abstract}
Observed relative humidity variations on the coastal ocean of the West Florida Continental Shelf (WFS) are examined over the 5-yr period 1998-2003. Despite considerable daily variability within seasons, the monthly mean values are nearly constant at about $75 \%$. Summertime specific humidity is twice that during winter, so high air temperatures are responsible for the low summer monthly mean relative humidities. Winter has the greatest relative humidity variability; values range from less than $50 \%$ to over $100 \%$ as extratropical fronts move over the WFS. Saturation (and fog) occurs as warm moist air passes over colder water. Two different sensors, mounted on multiple moorings, were used to make these observations. Monthly mean values from the Rotronics MP-100F are higher than the Hygrometrix 1020SHT. In addition to sensor differences, a contributing cause to this offset appears to be the locations chosen for sensor deployment. NCEP reanalysis climatology over the WFS and land-based coastal data both show an annual cycle in monthly mean relative humidity, with higher values in summer, suggesting that the reanalysis field is influenced by land. Air-sea fluxes over the WFS are sensitive to small spatial variability in the coastal ocean and atmosphere. The large grid spacing of the NCEP reanalysis does not capture this variability. The lack of coastal ocean data for assimilation biases the NCEP reanalysis fields toward land-based measurements. Increased spatial coverage via evolving Coastal Ocean Observing Systems should remedy this problem by providing required information for describing and understanding the complicated ocean-atmosphere interactions that occur on continental shelves.
\end{abstract}

\section{Introduction}

Latent heat flux from the ocean to the atmosphere fuels the earth's climate engine, and humidity is a primary factor in determining this flux. Here we describe relative humidity observations made from an array of moorings on the West Florida Continental Shelf (WFS), located on the east side of the Gulf of Mexico (hereafter Gulf). The WFS is gently sloping and extends about $200 \mathrm{~km}$ from the coastline to the shelf slope. Weather systems affecting the eastern Gulf come from the north (continental polar air) throughout the year, and also from the western Gulf in the winter (maritime polar air originally from the Pacific), with the maximum number of fronts arriving during December and March (Henry 1979). The average number of frontal systems over Florida and the northern Gulf in the winter is 7-8 (DiMego et al. 1976), occurring on time

Corresponding author address: Jyotika I. Virmani, College of Marine Science, University of South Florida, 140 Seventh Ave. S., St. Petersburg, FL 33701.

E-mail: jyotika@marine.usf.edu scales of 4-10 days. Large heat fluxes on the WFS occur during the passage of extratropical fronts (Price et al. 1978; Virmani and Weisberg 2003). The Loop Current advects warm Caribbean waters into the eastern Gulf, resulting in large latent heat fluxes east of the Mississippi River delta in the winter. Coastal waters on the shelf can be up to $10^{\circ} \mathrm{C}$ lower than mid-Gulf waters as a result of coastal upwelling on the WFS and surface heat flux in winter and spring. These temperature differences produce sea surface temperature (SST) gradients and air-sea flux variations that impact the climate of the Gulf. In turn, moisture fluxes from the Gulf influence the climate of adjacent landmasses, especially the central United States (Rasmusson 1967; Higgins et al. 1996). Locally, the surface heat flux is responsible for seasonal transitions in WFS ocean temperature in spring and autumn with ocean dynamics playing a role in synoptic-scale variability (He and Weisberg 2002, 2003; Virmani and Weisberg 2003).

There are few observations of relative humidity (RH) in subtropical coastal environments. Breaker et al. (1998a,b) describe some humidity data collected from two National Data Buoy Center buoys in the 
northwestern Gulf of Mexico (between $25^{\circ}$ and $28^{\circ} \mathrm{N}$ ), in water depths of 120 and $3200 \mathrm{~m}$. The dominant variability in specific humidity is on synoptic time scales and is associated with passing fronts between September and November. Complementing this, the present study provides a description of the annual cycle of RH on the WFS, a subtropical coastal ocean, with emphasis on the winter season when fog may occur.

Many studies of RH in the lower troposphere and coastal regions pertain to understanding fog in the extratropics (e.g., Telford and Chai 1993; Roach 1995). Coastal ocean fog can be formed in many ways. Fog formed on land may be advected offshore by nocturnal land breezes (Pilié et al. 1979). Stratus cloud lowering over the water (Pilié et al. 1979) or the onshore movement of marine stratocumulus clouds via sea breeze or orographic effects from coastal mountain ranges (Cereceda and Schemenauer 1991) result in fog. Radiative cooling of near-surface air may also produce fog (Emmons and Montgomery 1947; Roach 1995). In winter, cool surface air over warmer water promotes evaporation and convective mixing and creates fog (Pilié et al. 1979). In summer warm moist air gets cooler as it passes over cold water and produces large regions of persistent, dynamically stable, dense fog (Stone 1936; Noonkester 1979; Roach 1995; Lewis et al. 2003). The location and features of the coast determine the season and method of fog formation (e.g., Leipper 1994).

Marine fogs (visibility $<1 \mathrm{~km}$ ) form in $100 \% \mathrm{RH}$ by condensation on salt nuclei and continue to grow in supersaturated conditions (Woodcock et al. 1981). Fog may form without supersaturated conditions (Woodcock 1978) as a mixture of haze and fog particles (Gerber 1981). The time it takes for fog to grow depends on the number and size of nuclei available (Woodcock 1978), but saturated air needs to persist for at least $10^{3}$ $\mathrm{s}$ in order to allow salt nuclei to grow to fog droplet size. Fog layers are isothermal (Goodman 1977), have low wind speeds (Gerber 1981), and very little turbulent mixing (Lala et al. 1975). The concept of supersaturation has been problematic because humidity is expressed as a percentage that, by definition, cannot exceed saturation at $100 \%$. Additionally, land-based U.S. radiosondes have had problems recording high relative humidity values, returning $96 \%-98 \%$ measurements when they should have returned $100 \%$ or higher values (Golden et al. 1986; Liu et al. 1991; Garand et al. 1992). Despite this, supersaturation has been observed in fog. The nomenclature used is that supersaturation $(S)$ is expressed as a percentage value above $100 \%$. Hudson (1980) recorded $1 \% S$ off the Oregon coast. Meyer et al. (1980) measured $0.12 \% S$ in a radiation fog. Gerber
(1981), using a saturation hygrometer specifically designed to measure relative humidity between $95 \%$ and $105 \%$, observed $0.4 \% S$.

Early maps of fog frequency around the United States show a winter maximum, with 10-15 days annually, of heavy fog in west-central Florida (Stone 1936). Due to a lack of data over water, Stone infers a January maximum over the WFS. These numbers differ from subsequent maps because of the number and types of weather stations used, and because the definition of heavy fog has changed. More recent estimates show 20-30 days of heavy fog per year over central Florida (Court and Gerston 1966; Peace 1969).

In addition to describing the observed annual cycle in RH over the WFS, we made two observations regarding RH measurements that warranted further investigation: 1) the two different meteorological packages used to collect data showed an offset on a monthly average; and 2) the winter months showed relative humidities exceeding $100 \%$. The following section describes the data. Section 3 then describes the observed annual cycle. The difference between the two meteorological packages and details of the observed high $\mathrm{RH}$ are discussed in sections 4 and 5, respectively. Section 6 summarizes our findings.

\section{Data}

Since 1998 the Ocean Circulation Group (OCG) in the College of Marine Science, University of South Florida, has maintained an array of up to 14 moorings on the WFS. The deepest and shallowest moorings were at the 150- and 10-m isobaths, respectively. All the moorings measured current velocities, water temperature, and salinity. Six moorings carried meteorological packages that measured wind velocity, air temperature (AT), SST, RH, and barometric pressure (BP); some also had rainfall and shortwave and longwave radiation sensors. Figure 1 shows the location of these moorings and indicates which had either Coastal Environmental Systems (CES) Weatherpaks (triangles) or (Woods Hole Oceanographic Institute) WHOI-designed Improved Meteorological/Air-Sea Interaction Meteorological (IMET/ASIMET) sensor suites (squares). The Weatherpaks used a Hygrometrics 1020SHT Relative Humidity Sensor and a YSI 44018 Air Temperature Sensor. The RH sensor operates by measuring the hygromechanical stress of cellulose crystallite structures that absorb moisture. The IMET sensor suite used an ALDEN Relative Humidity Module (model 7030-A), which has a Rotronics MP-100F Humidity-Temperature Probe. This uses a C- 80 HYGROMER humidity sensor that measures changes in capacitance as a thin 


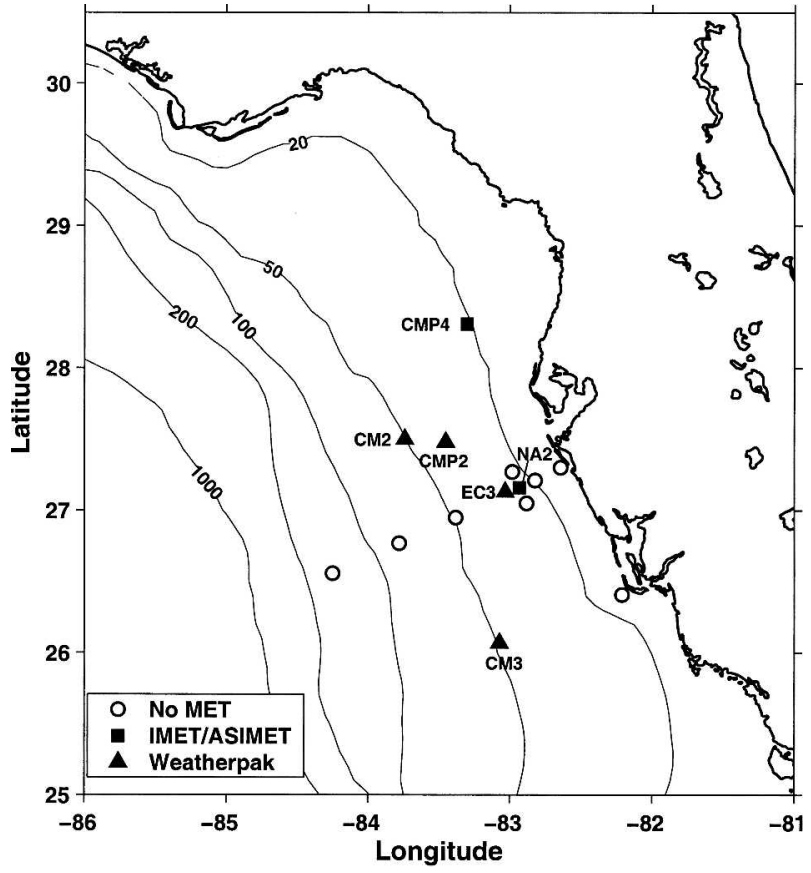

FIG. 1. Mooring locations on the WFS.

polymer film absorbs water vapor. These two sensors operate under different principles. The Hygrometrics is classified as an organically based sensor, while the Rotronics is a thin film capacitive sensor (Crescenti et al. 1990). The ASIMET package uses the same sensors as the IMET but is manufactured by Star Engineering instead of ALDEN. All RH sensors were located within an aspirated solar radiation shield to protect them from the effects of solar radiation and precipitation. The Weatherpak sensor was mounted $3.2 \mathrm{~m}$ above sea level and the IMET/ASIMET sensor was $2.3 \mathrm{~m}$ above sea level. The Weatherpak calibrations were conducted at CES, and the IMET/ASIMET calibrations were carried out at WHOI. Measurements from the Weatherpaks were made every $15 \mathrm{~min}$. Measurements from the IMET/ASIMET were made every 20 min. In addition to information being stored in the instruments, these data were transmitted back to the OCG via the GOES East satellite.

Long-term RH observations in a marine environment are difficult because of potential contamination by sea spray, heating by solar radiation, length of the deployment, and sensor calibration issues. Muller and Beekman (1987) tested eight RH sensors for reliability at various humidities and temperatures, and for longterm endurance. One of the sensors tested was the Rotronics hygromer, the humidity sensor in the IMET/ ASIMET. They found these sensors to be reliable, except in temperatures of $-20^{\circ} \mathrm{C}$, with no hysteresis ef- fects occurring after saturation. Although there has been one report of hysteresis effects at high humidities and very low temperatures for the Rotronics MP-100 based on data collected during the Humidity Exchange over the Sea (HEXOS) experiment in 1986 (Katsaros et al. 1994), other studies have not found any evidence of this (e.g., Breaker et al. 1998a). Subsequent manufacturing improvements to the MP-100 sensor may have eliminated this problem (Breaker et al. 1998b), making these sensors more reliable at high humidities. Crescenti et al. (1990) also tested various sensors prior to developing the IMET package. Among those tested was the Hygrometrix 8503A, which is a cellulose crystallite sensor and is therefore a kin of the Hygrometrics 1020SHT (manufactured by Hygrometrix) currently used in the Weatherpaks. The Hygrometrix sensor they tested was insensitive to humidities above $90 \%$ and exhibited hysteresis after exposure to high humidities. They concluded that cellulose crystallite sensors were not appropriate for use at sea. However, extensive developmental testing by Hygrometrix (Fenner 1973) and numerous oceanographic applications have shown the reliability of this type of sensor (R. Fenner 2004, personal communication). Our measurements returned similar values between both sensor types (within a few percent).

\section{Annual cycle}

Monthly means of the observed RH, BP, AT, and SST from 1999 to 2003 for all moorings are shown in Fig. 2. Generally the values between the moorings agree fairly well. Between 2000 and 2003, there is an offset in the monthly mean RH measured by the Weatherpaks (solid) and the IMET/ASIMET (dash) sensors, with the IMET/ASIMET values being $4 \%-8 \%$ higher than the Weatherpaks. This offset was present despite calibration efforts so it was difficult to determine which value was correct and this issue will be addressed in section 4. There was also a calibration problem with the BP sensors at two moorings (NA2 and EC3) in 2000 that was subsequently rectified. Hurricanes and tropical storms result in a yearly pressure minima in early autumn, suggesting that the monthly means are biased by a few strong events. The temperature sensors on all moorings agree with each other. The CMP4 mooring temperatures are lower in the winter of 2003, but as this is seen in both air and sea surface temperatures it is a genuine feature at the mooring location on the WFS. There is very little interannual variability apparent in the monthly mean RH or BP but there is some year-to-year variation in the temperature data. 


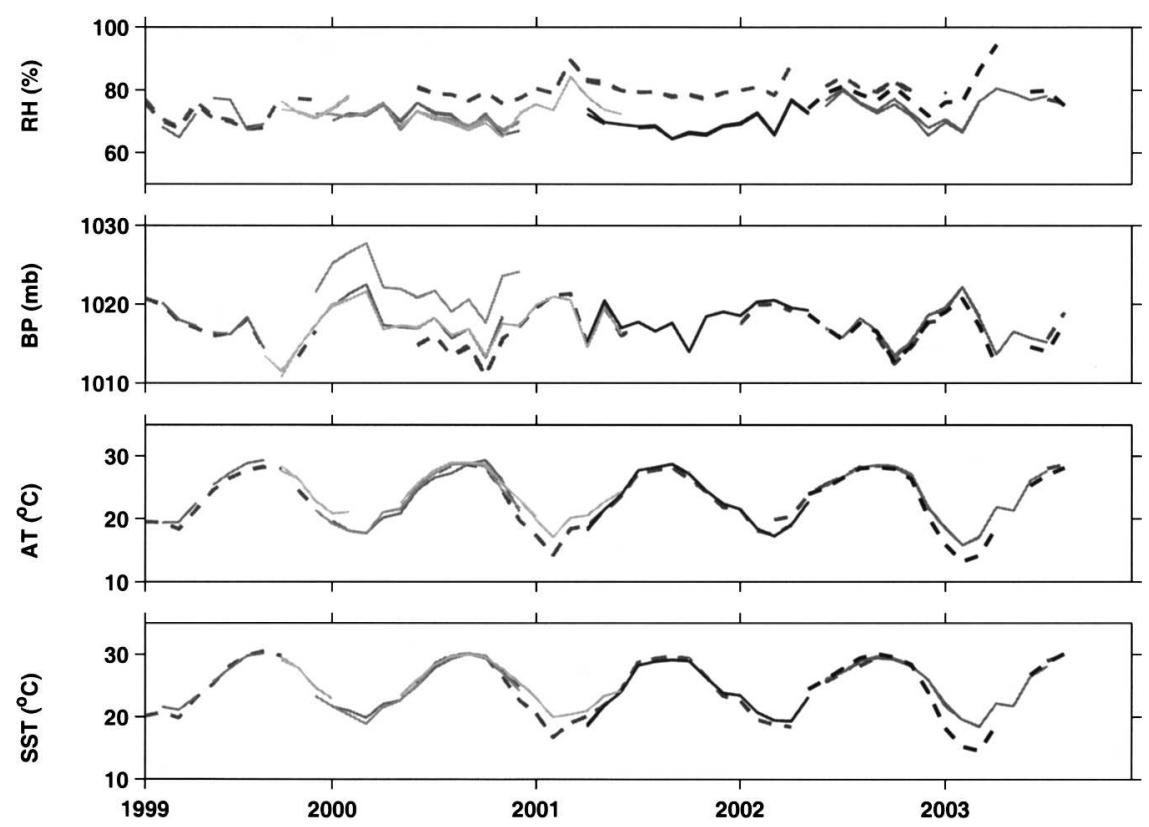

FIG. 2. Monthly mean RH, BP, AT, and SST calculated from Weatherpak (solid) and IMET/ASIMET (dashed) data. Individual moorings are represented by varying grayscale lines.

Table 1 shows the mean and standard deviations of RH per season and on an annual basis for the Weatherpaks, the IMET/ASIMET, and for all moorings combined. The values are calculated using all the available data (real time and stored). The average annual RH on the WFS measured by the Weatherpaks is $\sim 72 \%$, measured by the IMET/ASIMET is $\sim 78 \%$, and for all moorings combined it is about $73 \%$. The later value is biased toward the lower Weatherpak readings because the array has a larger number of Weatherpak sensors compared to the IMET/ASIMET. The approximate instrument error range given by the manufacturers is $\pm 4 \%$ for the Hygrometrix and $\pm 2 \%$ for the Rotronics. Our results indicate that the Weatherpak is not as unreliable at sea as some studies might suggest. The an-

TABLE 1. Mean and standard deviaiton of RH (\%) from 1999 to 2003 .

\begin{tabular}{lccc}
\hline & Weatherpak & IMET/ASIMET & All moorings \\
\hline $\begin{array}{c}\text { Winter } \\
\quad \text { Jan-Mar) }\end{array}$ & $74.0 \pm 13.7$ & $78.5 \pm 12.0$ & $75.2 \pm 13.2$ \\
$\begin{array}{c}\text { Spring } \\
\quad \text { (Apr-Jun) }\end{array}$ & $71.7 \pm 9.5$ & $78.1 \pm 8.3$ & $73.4 \pm 9.2$ \\
$\begin{array}{c}\text { Summer } \\
\quad \text { (Jul-Sep) }\end{array}$ & $69.9 \pm 6.4$ & $77.4 \pm 5.3$ & $72.0 \pm 6.1$ \\
$\begin{array}{c}\text { Autumn } \\
\quad(\text { Oct-Dec) }\end{array}$ & $69.9 \pm 11.2$ & $76.9 \pm 10.6$ & $71.8 \pm 11.1$ \\
Annual & $71.5 \pm 10.1$ & $77.7 \pm 8.7$ & $73.2 \pm 9.4$ \\
\hline
\end{tabular}

nual in situ values are slightly lower than the Comprehensive Ocean-Atmosphere Data Set (COADS) climatological estimates for the Gulf of Mexico (Peixoto and Oort 1996). All of our in situ sensors show greatest variability during the winter and least variability during summer (Fig. 3). The highest RH values occur during winter and the lowest during autumn.

Relative humidity, a measure of the amount of water vapor in air at a given temperature, is not the best indicator of the true water vapor content in air because of its temperature dependence. Low relative humidity values are a result of less water vapor in the air or high temperatures, and conversely for high relative humidity values. Specific humidity, the mass of water vapor per unit mass of air, is a better indicator. The monthly mean specific humidity, calculated between 1999 and 2003 from the in situ WFS data (Fig. 4), shows an annual cycle with twice as much water vapor in the summer as in the winter. This suggests that the low $(\sim 75 \%)$ monthly mean RH during the summer over the WFS is a consequence of high air temperatures. The winter RH values are more complicated. The AT and water vapor are low so the RH may not necessarily be any higher than in the summer, but large fluctuations are seen as a result of synoptic fronts that bring cold dry air over Florida and the Gulf, varying the $\mathrm{RH}$ from around $100 \%$ to less than $50 \%$. On a monthly average these extremes cancel out to give the observed mean values. 

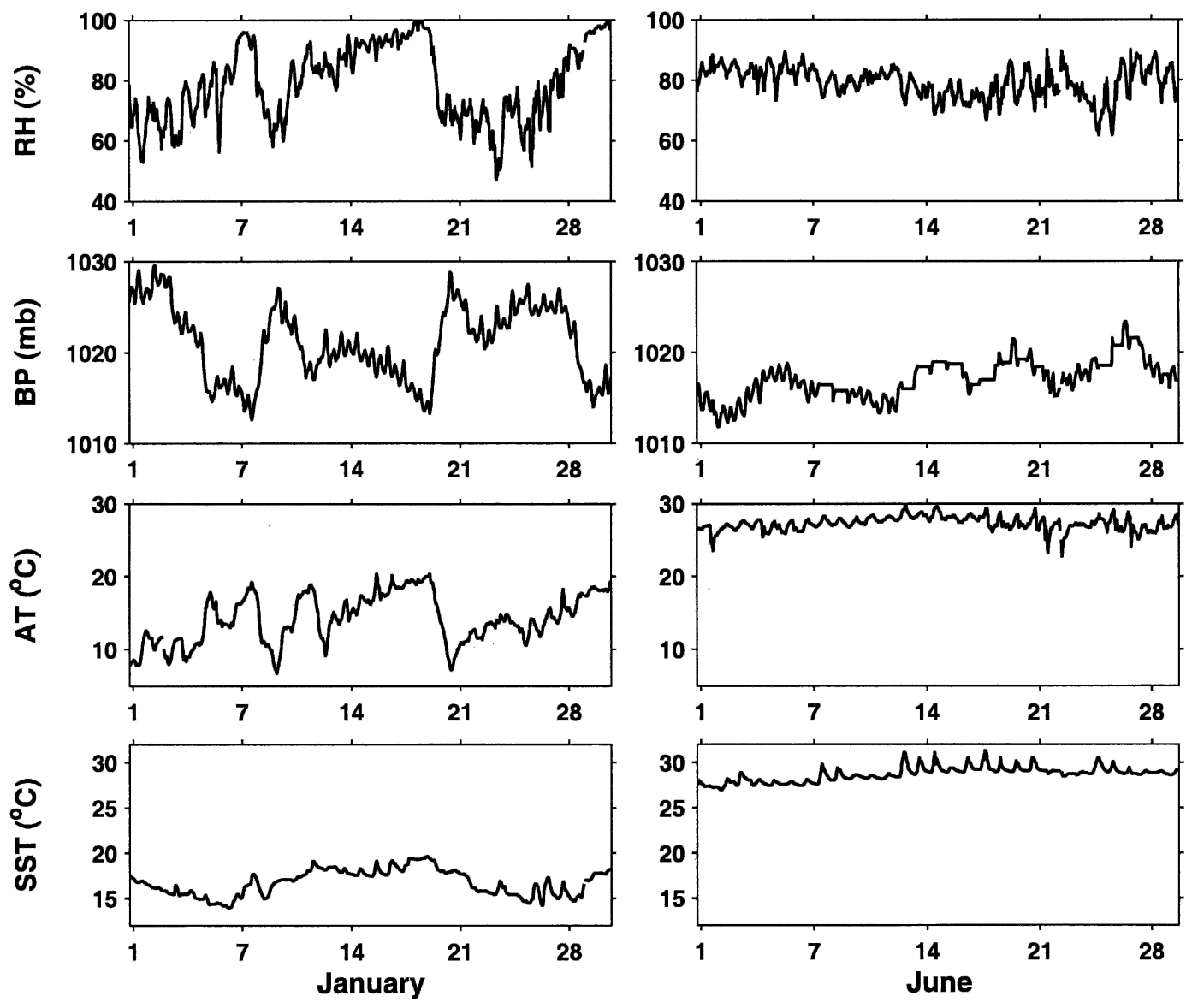

FIG. 3. The RH, BP, AT, and SST at NA2 in (left) Jan and (right) Jun 2001.

The wintertime RH fluctuations are discussed further in section 5 .

Climatologies of the multiyear in situ observations of RH and AT (Fig. 5) were computed by taking the means of each month over all years. The mean standard deviation per month over the time record shows that the largest variations occur in January and the smallest in July. Also shown are the National Centers for Environmental Prediction (NCEP) reanalysis RH and AT climatologies, calculated using monthly means from 1998 to 2003 to approximately coincide with our observation period. The NCEP reanalysis grid is $2.5^{\circ}$ latitude by $2.5^{\circ}$ longitude so only six grid points frame our observation area. The NCEP reanalysis data have been interpolated to each mooring location and then averaged. The in situ RH climatology does not exhibit a noticeable annual cycle unlike the NCEP RH climatology, which is higher during summer. The NCEP climatology has a larger annual cycle at the grid point closest to land $\left(27.5^{\circ} \mathrm{N}, 82.5^{\circ} \mathrm{W}\right)$ and a smaller annual cycle at the shelf break $\left(27.5^{\circ} \mathrm{N}, 85^{\circ} \mathrm{W}\right)$. To determine if the difference between the RH climatologies were due to differences between the in situ and reanalysis AT or water vapor content, the in situ RH and AT were used to calculate specific humidity, which was then used with the NCEP AT to calculate RH (Fig. 5). The difference between the observed and recalculated RH climatologies is due to a difference in the water vapor content between the observed and reanalysis fields. During the summer months (June-August) over $60 \%$ of the difference between the observed and NCEP RH climatologies can be accounted for by differences in water vapor. During winter and spring, the RH difference is almost entirely due to differences between reanalysis and observed AT.

Climatologies of onshore $\mathrm{RH}$ were calculated using monthly mean air and dewpoint temperatures from the National Data Buoy Center's Coastal-Marine Automated Network (C-MAN) Venice (VENF1) coastal station between 1998 and 2002 (Fig. 6). The dewpoint temperature, a measure of air moisture, is the air temperature at which saturation is reached (assuming constant pressure and water vapor). A high dewpoint temperature indicates more moisture in the air. The annual 


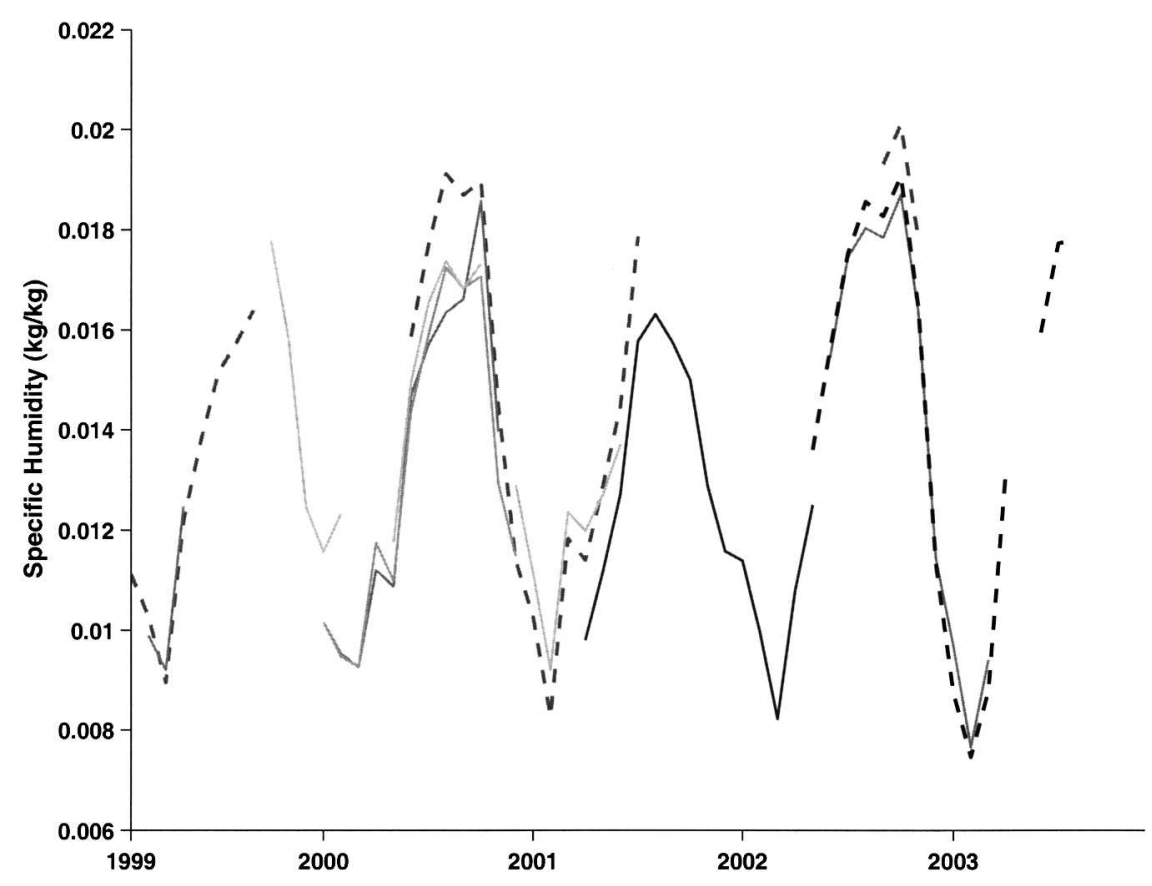

FIG. 4. Monthly mean specific humidity calculated from Weatherpak (solid) and

IMET/ASIMET (dashed) data. Individual moorings are represented by varying grayscale lines.

cycle in this coastal RH is similar to the NCEP climatology and indicates that NCEP reanalysis values over the WFS are influenced by land. The NCEP reanalysis field is the product of a coupled ocean-atmosphere model with data assimilation (Kalnay et al. 1996). Given the paucity of available data over the coastal oceans, it is not surprising that the NCEP reanalysis over the WFS is biased toward land measurements. Ad-
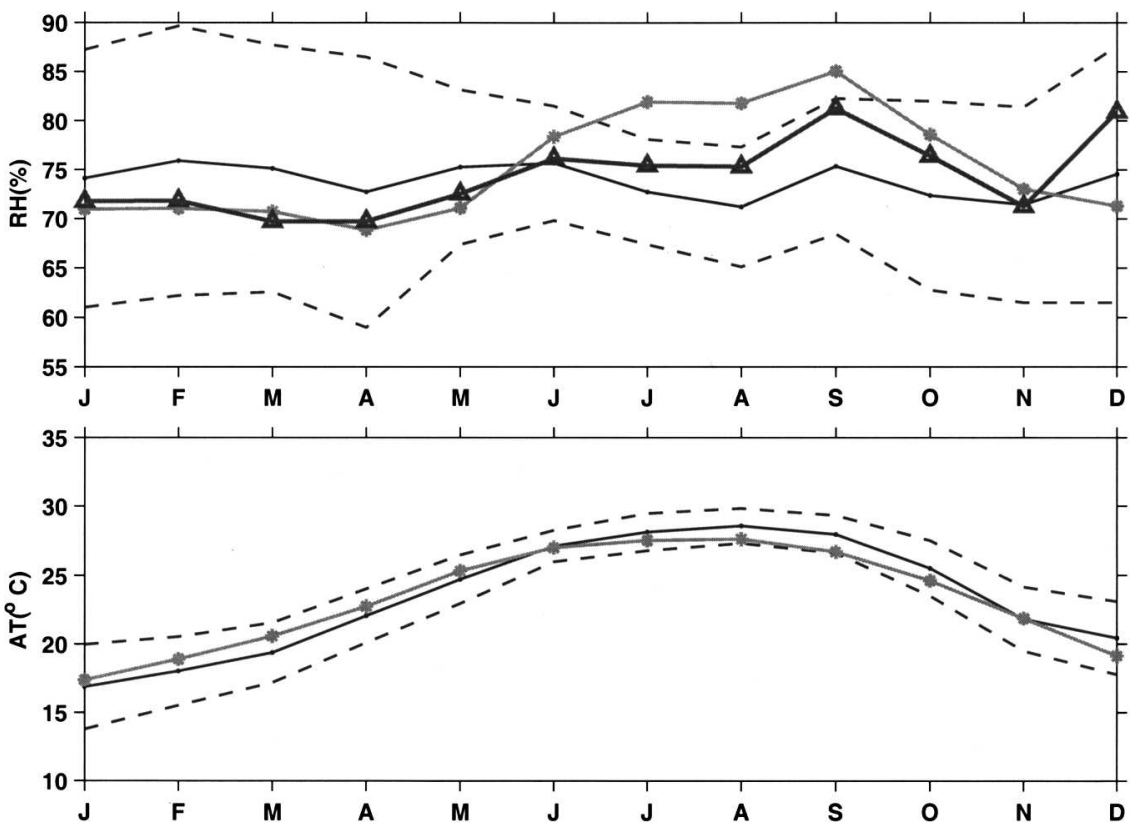

FIG. 5. Climatologies of RH and AT calculated from in situ measurements (dark solid) with one standard deviation (dark dash). NCEP reanalysis RH and AT climatologies (light solid), calculated using monthly means from 1998 to 2003 interpolated to each mooring location and then averaged. The line with triangles is the RH calculated using NCEP AT and in situ specific humidity (calculated from in situ RH and AT). 

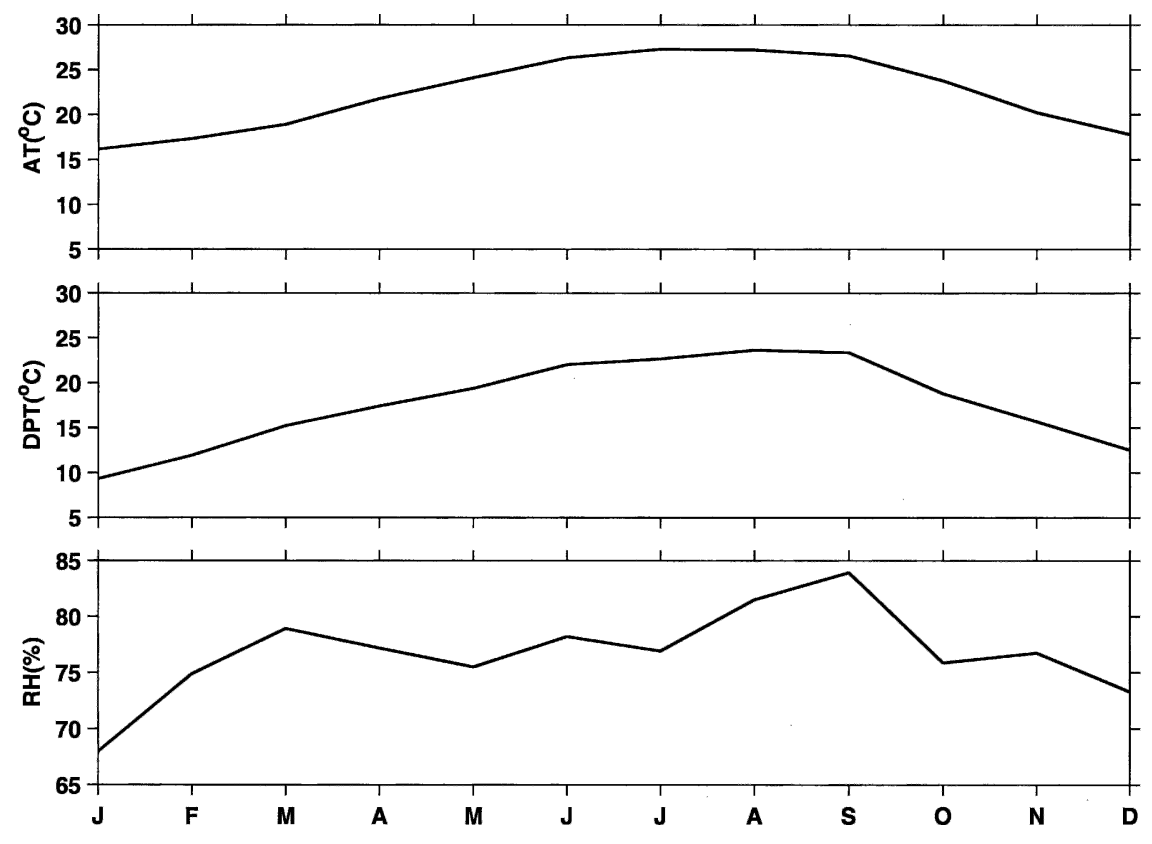

FIG. 6. Climatologies of AT, dewpoint temperature (DPT) and RH at NDBC Venice C-MAN Station, FL, calculated using data between 1998 and 2002.

ditionally, the large grid spacing of the reanalysis does not allow it to capture true variations over coastal ocean regions, which poses a problem for coastal ocean-atmosphere models.

\section{Weatherpak-IMET/ASIMET offset}

The monthly averaged IMET/ASIMET RH values are higher than the Weatherpak RH values (Fig. 2; Table 1). There are three possible explanations for this offset: (i) there is a problem in the way one meteorological packet measures RH; (ii) the sensors were at different heights, which lead to different relative humidities being measured; (iii) the sensors were located in different air-sea regimes on the WFS. This section investigates these three explanations. We conclude that the primary reason for the Weatherpak-IMET/ ASIMET offset is that the sensors are located in different air-sea regimes on the WFS, although we do not discount the fact that a difference in the sensor design may also be a factor and would require further testing in the future.

\section{a. Instrument differences}

The most likely cause for the offset between the two meteorological packages would, at first, appear to be a problem in the design or calibration of one. Multiple instruments have been used and all the sensors have been individually calibrated at various times through- out the five years so it seems unusual that there would be a persistent offset as observed. Additionally, although the monthly means show an offset, the hourly values do not; on some days the Weatherpak values are larger than the IMET/ASIMET values (Fig. 7).

The mean offsets between four moorings (two with Rotronics sensors and two with Hygrometrix sensors) were calculated over a period of 106 days (2544 hourly samples) in 2002 during which time the RH data return was good (Table 2). The offset between the two Rotronics sensors is greater than the offset between one of the Rotronics (CMP4) and one of the Hygrometrix (CM2) sensors. Likewise, the offset between the two Hygrometrix sensors is greater than the offset between one of the Rotronics (NA2) and one of the Hygrometrix (CM3) sensors. The greatest offsets are between the southernmost mooring (CM3) and all the instruments located to the north. The offsets between the northern moorings are smaller. This indicates that although there may be an instrument bias, it is not easily discernable with this data. It also suggests that the location of the instruments is important.

The correlation coefficients between moorings are also shown in Table 2. The lowest correlation is between the southern and northern mooring [a Rotronics (CMP4) and Hygrometrix (CM3) sensor]. The highest correlation is between the two closest moorings [a Rotronics (NA2) and Hygrometrix (CM2) sensor]. This further suggests that the observed RH differences de- 


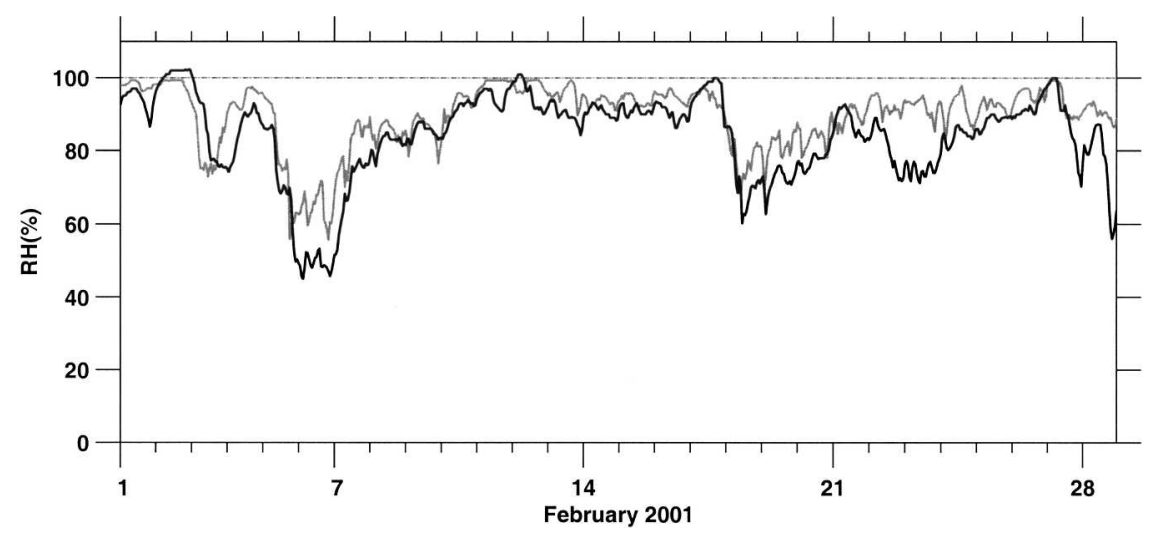

FIG. 7. The RH in Feb 2001 from CM3 (dark) and NA2 (light).

pend more on location than on sensor. The variance was also calculated at each mooring and increased with increasing distance offshore (not shown).

\section{b. Sensor height differences}

The Weatherpak sensors were mounted $3.2 \mathrm{~m}$ above sea level and the IMET/ASIMET sensors were mounted $2.3 \mathrm{~m}$ above sea level. To investigate the effect of this height difference, observations from the IMET/ ASIMET sensors were used to calculate the specific humidity and air temperature at the height of the Weatherpak sensors. We assume that water vapor and temperature varies with height according to a logarithmic profile

$$
q_{\mathrm{wp}}=q_{0}+\left(q_{*} / \kappa\right) \ln \left(z_{\mathrm{wp}} / z_{\mathrm{qr}}\right)
$$

and

$$
t_{\mathrm{wp}}=t_{0}+\left(t_{*} / \kappa\right) \ln \left(z_{\mathrm{wp}} / z_{\mathrm{tr}}\right)
$$

where $q$ is specific humidity, $t$ is temperature and $z$ is height. The subscripts "wp" refer to the Weatherpak sensor and " 0 " to the value at the sea surface. Here $\kappa$ is the von Kármán constant $(0.4), q_{*}$ is the humidity scale

TABLE 2. Mean offset and correlation matrix for RH sensors. Upper right of the diagonal represents the offsets between sensor pairs. Lower left of the diagonal represents correlation coefficients between sensor pairs.

\begin{tabular}{llllllr}
\hline \hline & & \multicolumn{2}{c}{$\begin{array}{c}\text { Rotronics } \\
\text { sensor }\end{array}$} & & \multicolumn{2}{c}{$\begin{array}{c}\text { Hygrometrix } \\
\text { sensor }\end{array}$} \\
\cline { 3 - 4 } & & CMP4 & NA2 & & CM2 & CM3 \\
\hline Rotronics & CMP4 & & -2.6050 & & 2.4746 & 8.2395 \\
$\quad$ sensor & NA2 & 0.6596 & & & 5.0874 & 10.6818 \\
Hygrometrix & CM2 & 0.6637 & 0.7183 & & 5.6864 \\
$\quad$ sensor & CM3 & 0.3932 & 0.5489 & & 0.5473 & \\
\hline
\end{tabular}

$\left(\mathrm{kg} \mathrm{kg}^{-1}\right), t_{*}$ is the temperature scale $\left({ }^{\circ} \mathrm{C}\right)$, and $z_{\mathrm{qr}}, z_{\mathrm{tr}}$ are the specific humidity and temperature roughness lengths, respectively. The scales $q_{*}$ and $t_{*}$ are calculated from

$$
q_{*}=\mathrm{C}_{\mathrm{E}}\left(\left|U_{z}\right| / \mathbf{u}_{*}\right)\left(q_{z}-q_{0}\right)
$$

and

$$
t_{*}=\mathrm{C}_{\mathrm{H}}\left(\left|U_{z}\right| / u_{*}\right)\left(t_{z}-t_{0}\right),
$$

where $\mathrm{C}_{\mathrm{E}}$ and $\mathrm{C}_{\mathrm{H}}$ are the dimensionless Dalton and Stanton numbers, respectively. The subscript " $z$ " refers to observed values, $U$ is the wind velocity, and $u_{*}$ is the surface friction velocity scale given by

$$
u_{*}=\left|U_{z}\right|\left(C_{D}\right)^{0.5},
$$

where $C_{D}$ is the neutral drag coefficient. Assuming that the transport of moisture and heat near the surface is dominated by wind shear over buoyancy effects, the parameterizations in (2a) and (2b) account for the effect of wind on the vertical profile of moisture and temperature.

The mean difference between the values at the IMET/ASIMET sensor height and the values scaled to the Weatherpak sensor height were $5.24 \times 10^{-5} \mathrm{~kg}$ $\mathrm{kg}^{-1}$ in specific humidity and $0.03^{\circ} \mathrm{C}$ in AT. These were at least two orders of magnitude smaller than the measured values and correspond to a $1.4 \%$ change in $\mathrm{RH}$, which is within the instrument error range.

\section{c. Air-sea regime differences}

Near the coast SSTs are generally colder in winter and warmer in summer. The northern Gulf waters get colder during winter, starting at the coast first and progressing farther offshore with each passing polar continental front. In spring, as solar radiation increases, the 


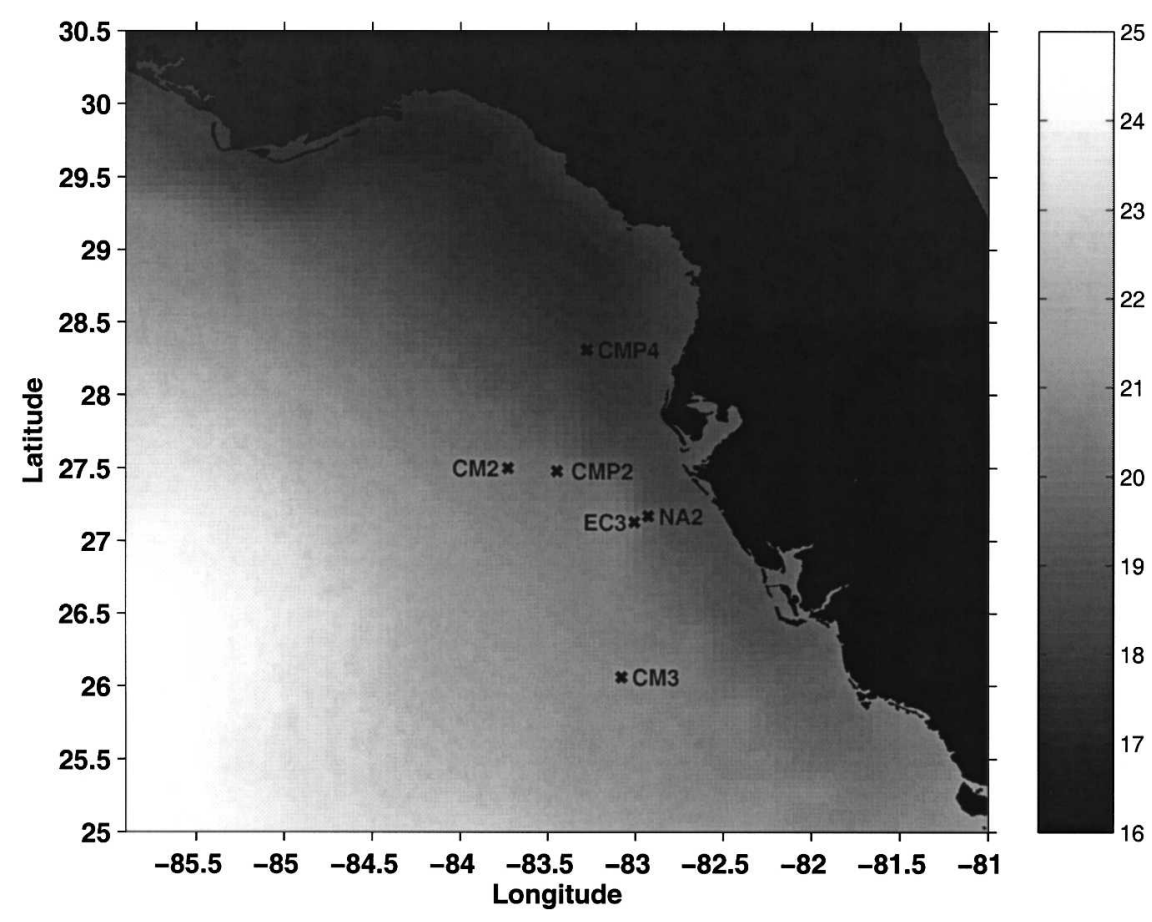

FIG. 8. Climatology of optimal interpolated cloud-free SST $\left({ }^{\circ} \mathrm{C}\right)$ for Feb, derived from AVHRR and TMI satellite data from 1998 to 2003 produced by Liu et al. (2004, manuscript submitted to J. Atmos. Oceanic Technol.) with WFS air-sea mooring locations overlaid.

near-coastal waters warm up first (Huh et al. 1978; He and Weisberg 2002). The WFS temperature field is further complicated by the shelf's north-south orientation, shallow cross-shelf gradient, ocean dynamics, and atmospheric forcing. For example, a seasonal midshelf cold tongue develops in spring as baroclinic pressure gradients are induced in response to temperature gradients formed by differential along and across shelf heating (Weisberg et al. 1996; He and Weisberg 2002). Model studies have demonstrated a climatological wind-driven preference for wintertime upwelling and summertime downwelling in the northeastern shelf (Yang and Weisberg 1999).

A review of the distribution of our instrumentation over the WFS shows that our IMET/ASIMET sensors are situated closest to the coast and farthest north, while the Weatherpak sensors are farther offshore and south. A climatology of optimal interpolated cloudfree SST maps for the WFS have been derived from the Advanced Very High Resolution Radiometer (AVHRR) and the Tropical Rainfall Measuring Mission (TRMM) Microwave Imager (TMI) satellite data from 1998 to 2003 (Liu et al. 2004, manuscript submitted to J. Atmos. Oceanic Technol.). During the winter the IMET/ASIMET sensors are usually in colder waters than the Weatherpak sensors (Fig. 8). The cooler water aids in cooling the marine boundary layer imme- diately above the sea surface relative to moorings located in warmer waters. This is conducive to generally higher $\mathrm{RH}$ observations at the moorings located in colder waters. The exception to this occurs during the passage of synoptic fronts in the winter when warm air is advected from the south, as discussed in section 5. The differing coastal air-sea environments in which the sensors are located provide the most compelling reason for the observed monthly $\mathrm{RH}$ offset between the Weatherpak and IMET/ASIMET data.

\section{Winter relative humidity and supersaturation}

Synoptic weather systems over the WFS in winter cause large fluctuations in RH and therefore in latent heat flux from the ocean to the atmosphere (Virmani and Weisberg 2003). High RH results in small latent heat loss from the ocean and conversely for low $\mathrm{RH}$. Occasionally values of $100 \% \mathrm{RH}$ and higher (supersaturation) have been recorded at our moorings, followed by a drop of $40 \%-50 \%$. Supersaturation commonly occurs in clouds or fog and supersaturation values of $2 \%$ have been observed in the marine environment (Breaker et al. 1998a). The National Oceanic and Atmospheric Administration (NOAA) Storm Data reports (NCDC 1998-2003) summarize information on storms and unusual weather phenomenon collected by 

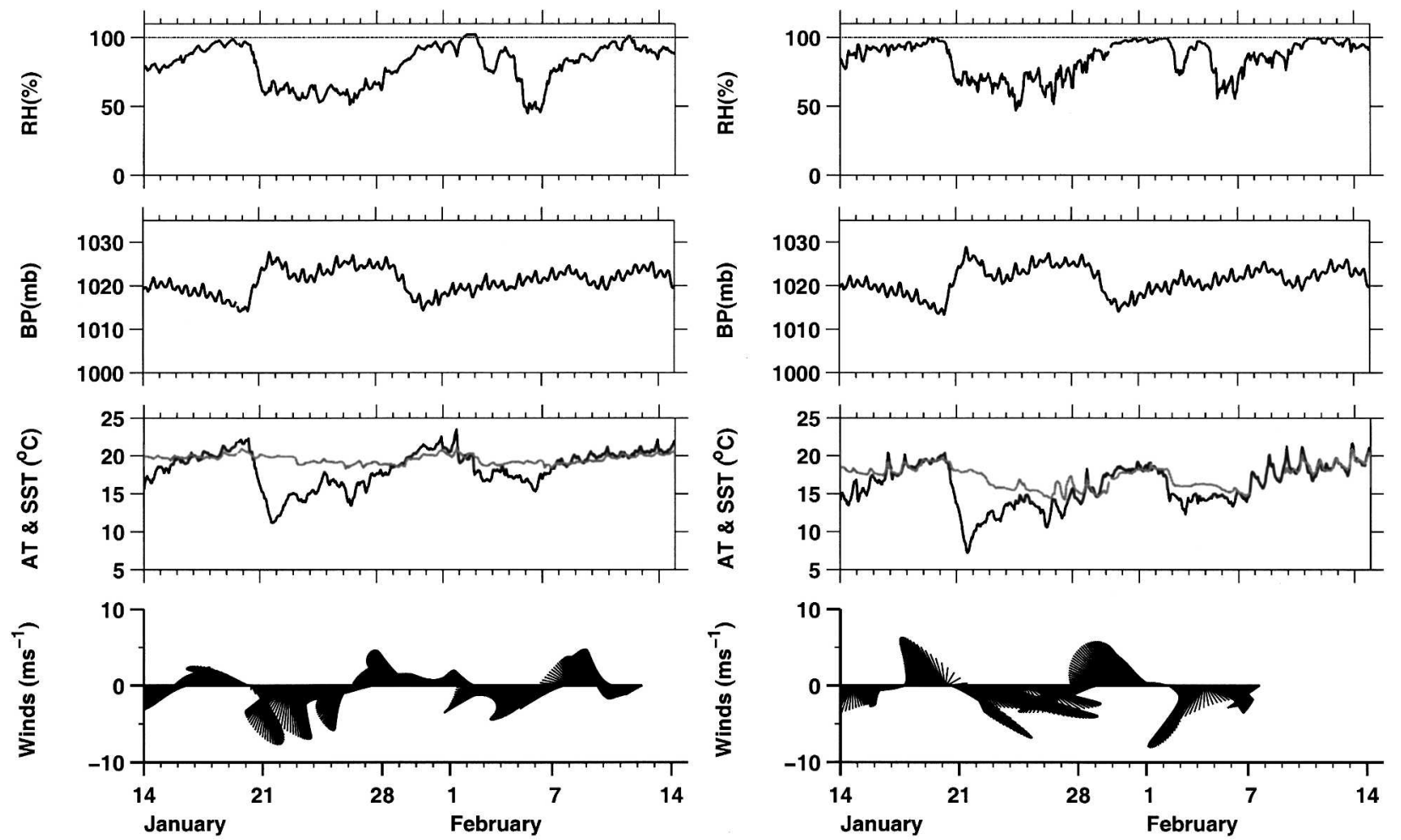

CM3

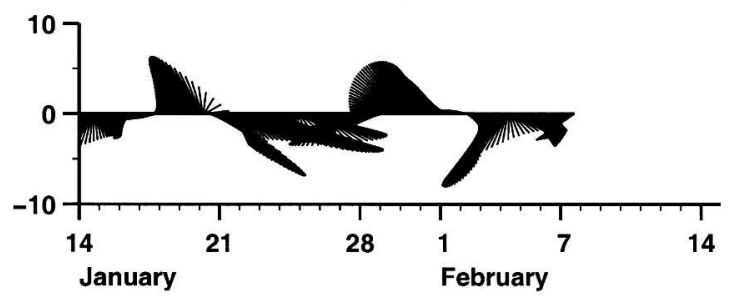

NA2

FIG. 9. The RH, BP, AT (dark), SST (light), and 36-h low-pass-filtered winds at (left) CM3 and (right) NA2 in Jan and Feb 2001.

the National Weather Service and the National Climatic Data Center (NCDC). Most of the information is from land-based observations. Reports from 1998 to 2003 show the presence of fog over west-central and southwestern Florida coastal counties during the days we observe supersaturation offshore. The closest atmospheric soundings to our moorings are from the Ruskin/Tampa Bay National Weather Service station. On foggy days these show that the atmospheric boundary layer is approximately $200 \mathrm{~m}$ thick.

In January and February 2001, RH exceeded 100\% at CM3 (Weatherpak) and almost reached $100 \%$ at NA2 (ASIMET; Fig. 9). At both locations the RH approaches $100 \%$ when AT equals or exceeds SST over a period of a few days. This occurs when northerly winds change to southerlies with passing extratropical fronts (Fernandez-Partagas and Mooers 1975), advecting warm air over colder waters. In advance of an approaching cold front, clockwise-turning winds bring warm air from the south (Price et al. 1978). In the wake of the front, northerly winds bring cold dry polar air and the RH rapidly drops to around $50 \%$. The cycle repeats itself; warm air, advected by southerly winds, lead to higher RH in advance of the next front. Synoptic weather maps from the NCDC-archived NCEP charts (Fig. 10) show that high RH observations (e.g., Fig. 7) generally occur in the presence of stationary or slow moving cold fronts. A rapidly moving front on 10-12 January (not shown) ensures that, although there are southerly winds, AT is only warmer than SST for a few hours and $\mathrm{RH}$ remains low.

A closer examination on smaller time scales shows that very high RH may also be observed when SST is slightly warmer than AT (Fig. 11). At midnight (all times are local time) on 2 February $2001 \mathrm{CM} 3$ recorded values of $100 \% \mathrm{RH}$ following a few hours of SST being warmer than AT. At this time, BP and SST are decreasing and AT is increasing. Initial $S$ is observed at 0200 local standard time (LST) when SST and AT are both at $19.9^{\circ} \mathrm{C}$. This is warmer than temperatures recorded in fog off the California coast by Goodman (1977). Values of $1 \% \mathrm{~S}$ persist while AT is greater than SST $\left(0.2^{\circ} \mathrm{C}\right)$ and the winds are weak southerlies (maximum $3 \mathrm{~m} \mathrm{~s}^{-1}$ ). Supersaturation increases to $2 \%$ at $0515 \mathrm{LST}$, as AT begins to decrease and become cooler than SST. These conditions remain for the following $9 \mathrm{~h}$ during which time the winds are weak southeasterlies (less than $4 \mathrm{~m} \mathrm{~s}^{-1}$ ). At $1300 \mathrm{LST}$, although SST is still warmer than AT, the winds begin rotating clockwise and become northerlies by 1500 LST. The maximum $S$ 
00Z February 2, 2001

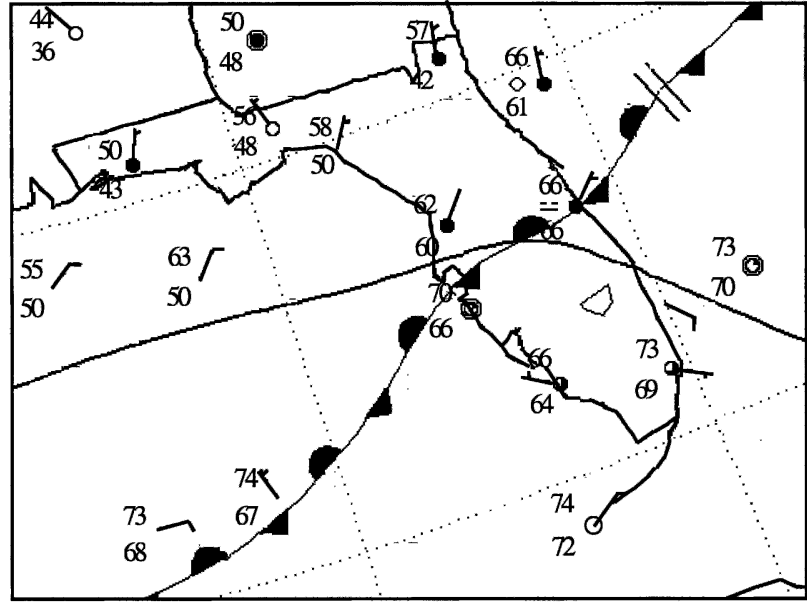

18Z February 17, 2001

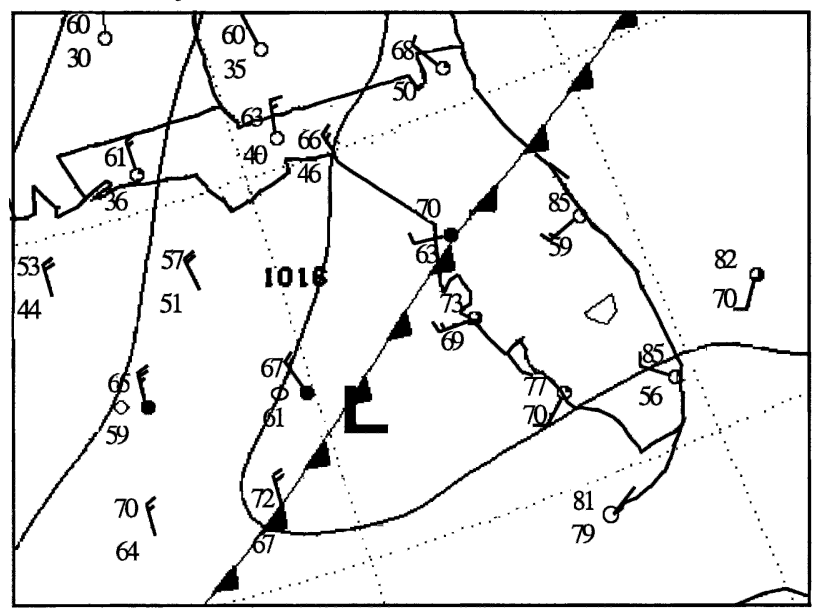

06Z February 12, 2001

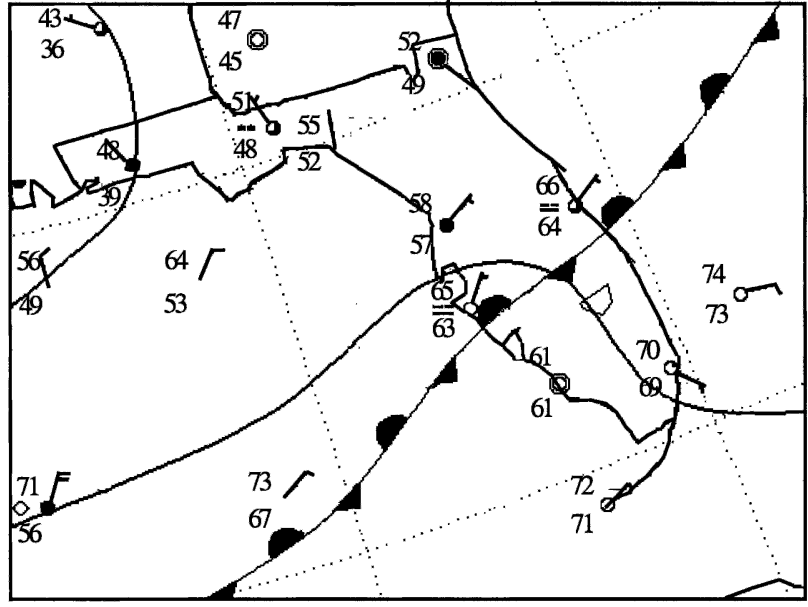

18Z February 27, 2001

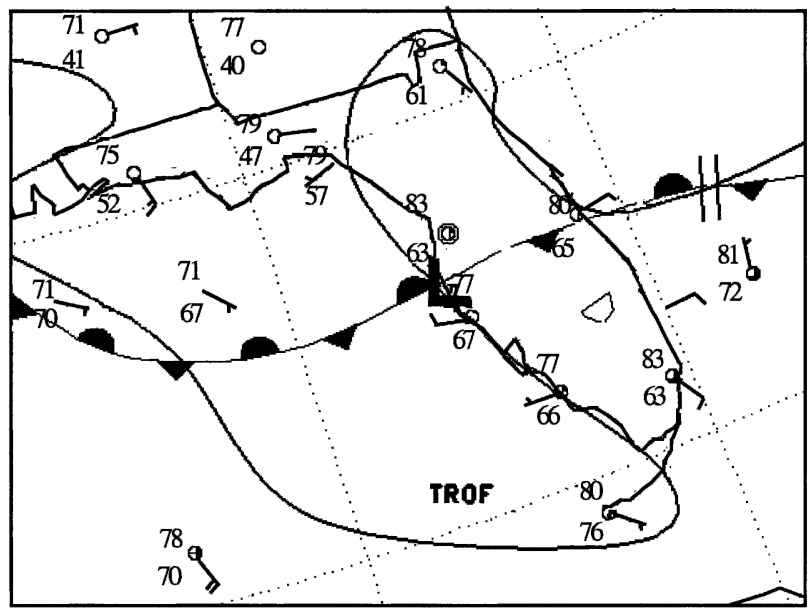

FIG. 10. Synoptic weather maps from the NCDC-archived NCEP charts for 4 days in Feb 2001 when high RH values were observed.

value recorded is $3 \%$, which occurs at 1600 LST when AT begins to decrease and the wind speed increases, and again between 1800 and 1845 LST immediately following the coldest AT. From 1845 to 2100 LST BP steadily increases and humidity decreases from $3 \% \mathrm{~S}$ to 99\% RH. On 2 February the air at NA2 remained unsaturated, but high values of $99.3 \%$ are recorded. Although NA2 recorded similar fluctuations in the wind and $\mathrm{BP}$, one difference between these two sites was that at NA2 AT never equaled or exceeded SST. The smallest SST-AT value $\left(0.07^{\circ} \mathrm{C}\right)$ occurred at the same time that $2 \% S$ was recorded at CM3. The NOAA Storm Data report for 2 February 2001 documents widespread dense fog over the west-central Florida coastal counties. It is possible that supersaturation was not observed at NA2 because of its proximity to land. We do not have the ability to measure the cloud condensation nuclei $(\mathrm{CCN})$ at these moorings, but speculate that a greater number of land-based $\mathrm{CCN}$ at NA2 prevented supersaturation at that location than farther offshore, at CM3.

Saturation was also observed at CM3 on 11-12 and 17 February (not shown) and coincided with observations of patchy dense fog over west-central and southwest Florida (NOAA Storm Data report). The RH values at NA2 reached a maximum of $99.4 \%$ on these days. Supersaturation was only observed on 11-12 February. In all cases SST was usually slightly greater than or equal to AT and wind speeds were low (less than 0.5 $\mathrm{m} \mathrm{s}^{-1}$ on 17 February). Observations of fog in wind speeds smaller than $0.5 \mathrm{~m} \mathrm{~s}^{-1}$ have also been recorded by Gerber (1981). The highest value of 3\% S measured by our sensor only existed for less than an hour. The ASIMET sensor used in February 2001 never recorded values greater than $99.4 \%$ but, as stated earlier, this may be due to its location. 


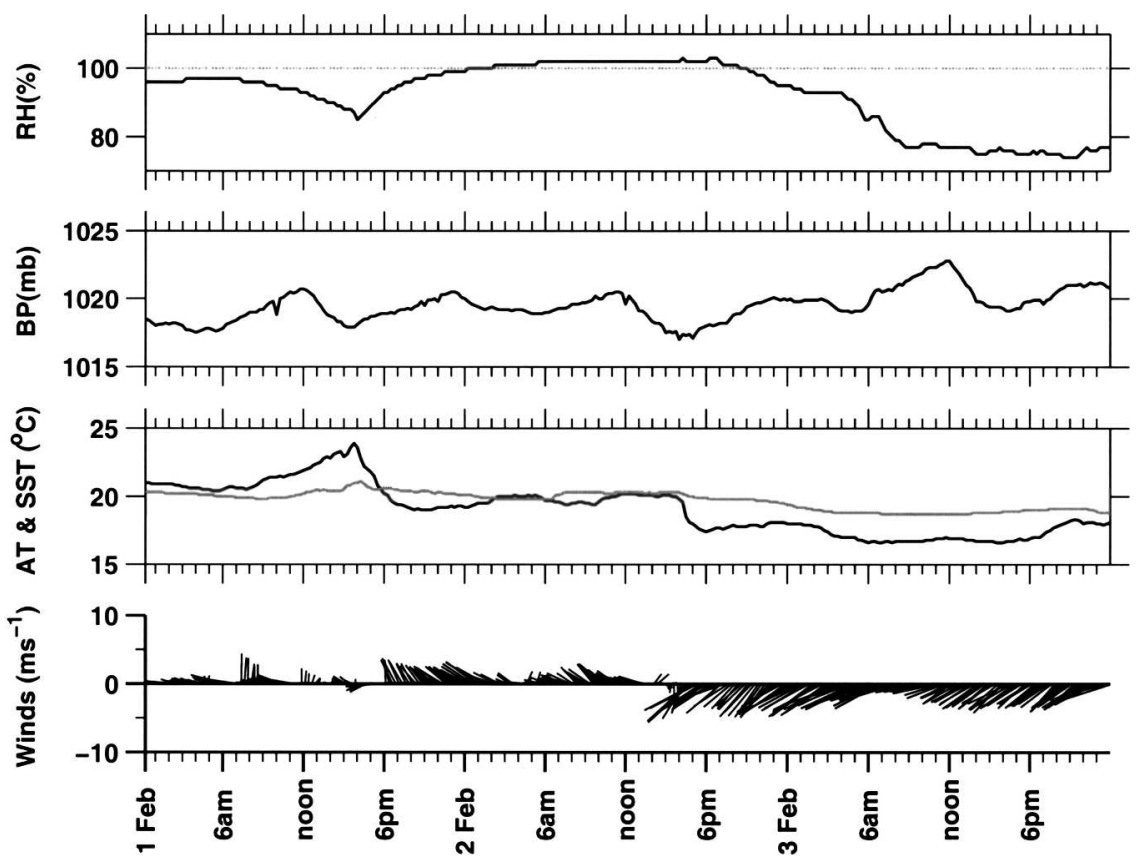

FIG. 11. Fifteen-minute observations of RH, BP, AT (dark), SST (light), and winds during 1-3 Feb 2001.

From Gill (1982) the observed BP (mb) and SST $\left({ }^{\circ} \mathrm{C}\right)$ can be used to calculate the saturation specific humidity at the ocean surface, $q_{w}$, and in air, $q_{a}$ :

$$
q_{w, a}=\left(0.62197 e_{w, a}\right) /\left(\mathrm{BP}-0.378 e_{w, a}\right),
$$

where $e_{w}$ and $e_{a}$ are the saturation vapor pressures at the ocean surface and in the air, respectively. There are many formulas for calculating $e_{w, a}$, but the difference between them is negligible $(<0.05 \%)$ at temperatures of $20^{\circ}-30^{\circ} \mathrm{C}$ (Elliott and Gaffen 1991). We use the Coupled Ocean-Atmosphere Response Experiment (COARE) algorithm (Fairall et al. 1996), which is based on Buck (1981):

$$
\begin{aligned}
e_{w, a}= & 6.1121 \times(1.0007 \\
& \left.+3.46 \times 10^{-6} \mathrm{BP}\right) \exp \left[17.502 T_{s, a} /\left(240.97+T_{s, a}\right)\right],
\end{aligned}
$$

where $T_{s}$ is SST and $T_{a}$ is AT.

The specific humidity at the sea surface, $q_{0}$, is

$$
q_{0}=K q_{w},
$$

where $K$ is a reduction factor for the saturation vapor pressure over saltwater. Assuming salinity is $35 \mathrm{ppt}, K$ $=0.98$. The specific humidity of air, $q$, is

$$
q=q_{a}(\mathrm{RH} / 100) \text {. }
$$

The specific humidity at the sea surface depends on SST and BP, and is independent of in situ RH, whereas the specific humidity of air depends on AT, BP, and RH. During times of high RH in January and February 2001 , the specific humidity of air $(q)$ is greater than the specific humidity at the sea surface $\left(q_{0}\right)$ at CM3 (Fig. 12). The plots in Fig. 13 show specific humidity values as a function of AT for February 2001 (top panel) and February 2003 (bottom panel). The solid black lines are the saturation specific humidity of air, $q_{a}$, calculated using (3) with in situ AT and BP from each mooring. The saturation specific humidity lines from each mooring overlap, as shown in the figure, and they denote the specific humidity at which air is saturated at a given AT. The dots are the specific humidity values of air, $q$, at each mooring calculated using (6). There are two things to note from this figure. The distribution of dots shows that the humidity-air temperature range at each mooring site varies, especially at lower humidities. For example, a specific humidity of $0.006 \mathrm{~kg} \mathrm{~kg}^{-1}$ occurs between $10^{\circ}$ and $14^{\circ} \mathrm{C}$ in February 2003 at CMP4, however at CM2 the same specific humidity is only found between $13^{\circ}$ and $16^{\circ} \mathrm{C}$. Conversely, if the AT is between $13^{\circ}$ and $16^{\circ} \mathrm{C}$, the specific humidity is higher at CMP4 than at CM2. Second, based on the definition of relative humidity (6), supersaturation (values above the saturation line) was observed in February 2001 at CM3, and the air at NA2 was almost saturated. In February 2003 the air at all moorings was near saturation at some point during the month and saturation was observed at CMP4. Interestingly, during these 


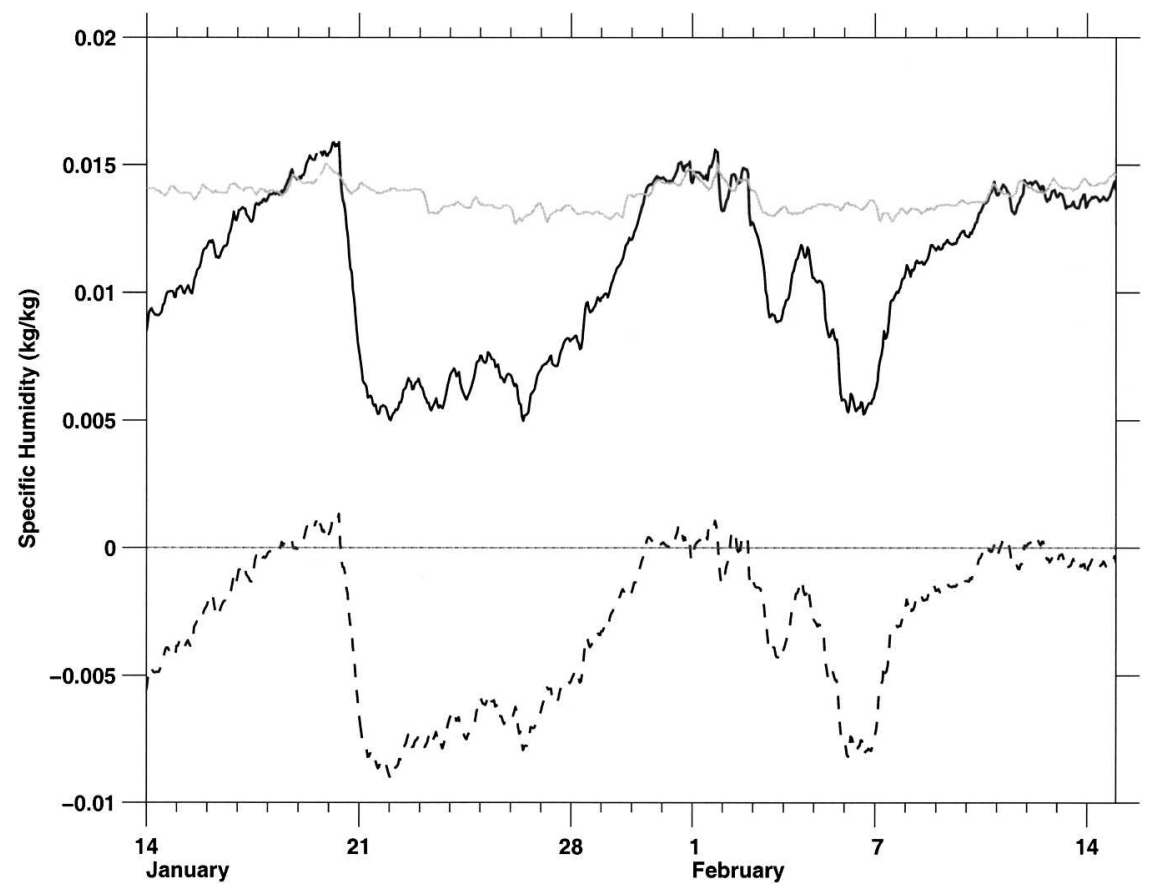

FIG. 12. Specific humidity in air (dark solid), at the sea surface (light solid), and their difference (dashed) calculated at CM3 in Jan and Feb 2001.

near-saturation events the $\mathrm{RH}$ value remained constant over many hours. This occurred simultaneously at multiple moorings using both ASIMET and Weatherpak sensors. One possible explanation for this is that there are small fluctuations in humidity that the instruments are incapable of resolving.

February 2001 was used to show examples of observations of high RH. The number of days with RH val-
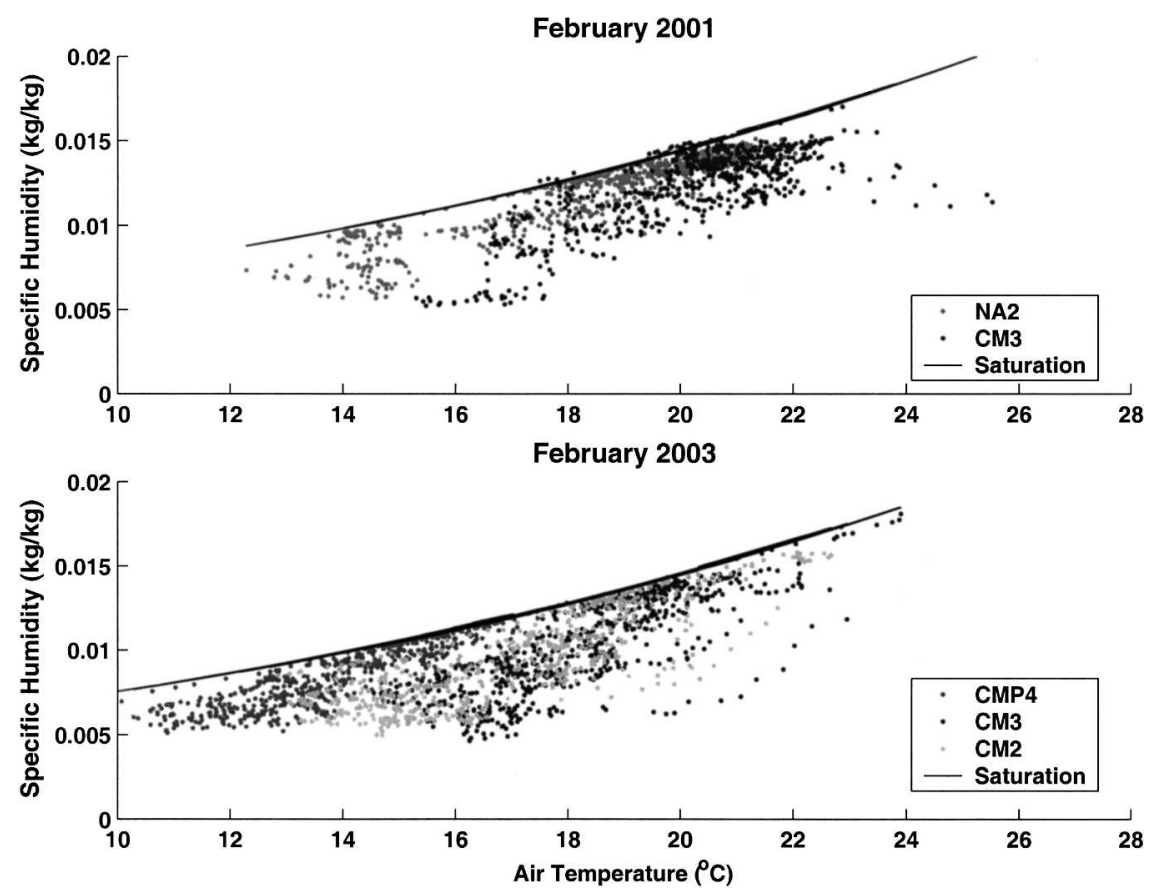

FIG. 13. Specific humidity vs AT at various moorings in (top) Feb 2001 and (bottom) Feb 2003. Saturation specific humidity (solid line) is also calculated from data. 


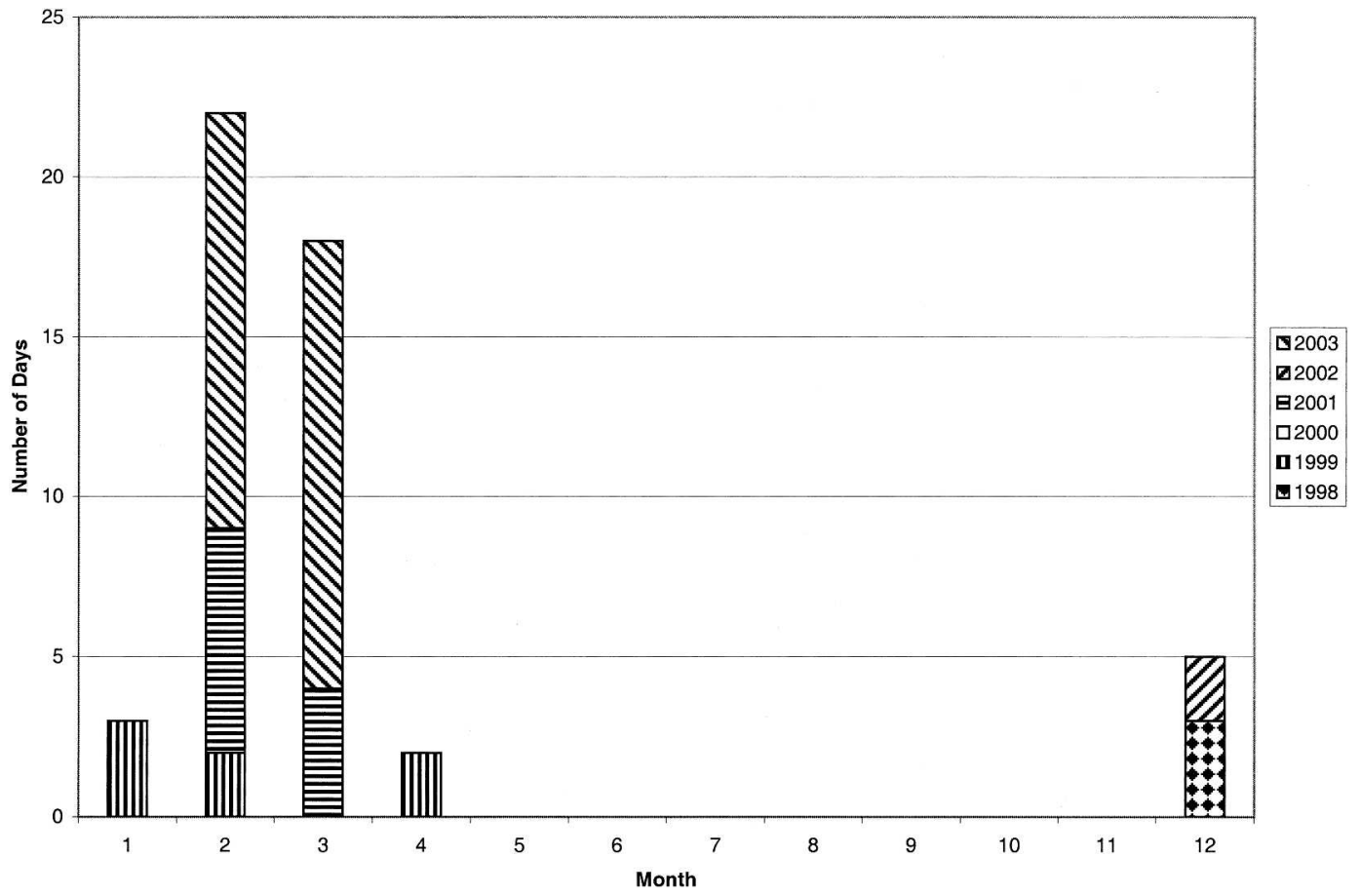

FIG. 14. Annual distribution of the number of days with observed relative humidity greater than $99 \%$.

ues greater than $99 \%$ was compiled to show the annual distribution of high RH (Fig. 14). The number of days in 1998 may be low because data were only collected for the latter part of that year. If there was only one measurement of high $\mathrm{RH}$ in the day it was not included. Very high RH values are observed in all years except 2000 and are a recurring feature during winter and early spring on the WFS. February and March have the greatest occurrence of high RH days.

\section{Conclusions}

Four years of meteorological measurements on the WFS have been used to describe the annual cycle in $\mathrm{RH}$ in a subtropical coastal ocean environment. The monthly mean values are approximately constant at about $75 \%$ throughout the year, but there is considerable daily and synoptic variability between seasons; winter has the greatest variability, summer has the least. Unlike these in situ data, NCEP reanalysis climatology and monthly mean land-based coastal data for the region show a summer maximum and winter minimum in RH, suggesting that the reanalysis field is influenced by land. The in situ NCEP reanalysis and landbased coastal annual cycle in monthly mean AT are similar, implying that the differences in $\mathrm{RH}$ are because of the water vapor. There are two problems in using NCEP reanalysis fields over coastal oceans: 1) the large grid spacing does not allow it to capture coastal ocean variability; and 2) the reanalysis fields are produced by a model with data assimilation, but the paucity of in situ data in coastal environments results in an intrinsic land or deep-ocean bias. Both of these issues need to be addressed in order to improve upon coastal ocean results from coupled ocean-atmosphere models. This provides added justification for emerging coastal ocean observing systems.

Although the monthly mean $\mathrm{RH}$ is constant during the year, the monthly mean specific humidity, calculated from in situ measurements, has an annual cycle with twice as much water vapor in the summer than the winter. This suggests that the monthly average summer $\mathrm{RH}$ of $75 \%$ is a consequence of high AT. In winter, $\mathrm{RH}$ varies according to synoptic fronts. High values are observed ahead of slow moving or stationary fronts, as southerly winds advect warm, moist air over colder water. During this time the RH can exceed $100 \%$ and we observe supersaturation values of up to $3 \%$. Over the WFS in winter dense fog may be formed in a dynamically stable atmospheric boundary layer as the warm overlying air is cooled by the sea surface. These types of fogs are more commonly observed in summer in the extratropics. Our observations show that, generally, high RH occurs when AT is close to or exceeds SST. However during a fog event SST may be slightly greater than AT and RH will still remain high or continue to 
increase. From our data we cannot determine if this increase is due to increased evaporation and convective mixing, or due to the radiative cooling of the air. A more detailed study under these conditions would be required to determine the exact cause. As the front passes, clockwise-rotating winds become northerly and $\mathrm{RH}$ decreases by $40 \%-50 \%$ as cold, dry air is brought into the region. These high/low RH fluctuations are observed every year in winter and early spring on the WFS, with February and March having the most days with RH greater than $99 \%$. Occasionally, during high RH, many hours of constant humidity are recorded simultaneously at multiple moorings. These may be because RH fluctuations are small and the sensors are incapable of detecting them. Further work needs to be done to determine the exact reason for the constant RH.

Two sensors are used to measure RH. Although the monthly average RH values from the IMET/ASIMET (Rotronics) sensors are higher than from the Weatherpak (Hygrometrix) sensors, regardless of the time of year, they agree to within a few percent suggesting that they are both capable of making measurements at sea. Part of the offset may be due to the different sensors used or to the calibration and sensor height above sea level; however, our analyses suggest that the most important factor is the location of the sensors on the WFS. The IMET/ASIMET sensors are positioned farther north and closer to shore than the Weatherpak sensors, and are therefore in different air-sea regimes. This study has shown the sensitivity of RH to small spatial variations in the coastal ocean environment. Thus, $\mathrm{RH}$ depends not only on the high-frequency variability in meteorological conditions, but also on the low-frequency variability in oceanic conditions, specifically SST, which is controlled by both surface heat flux and ocean circulation dynamics (He and Weisberg 2002, 2003; Virmani and Weisberg 2003).

People who live near the coast are affected by coastal ocean-atmosphere interactions; often conditions such as fog offshore determine the weather onshore. Careful attention must be paid to the spatial distribution of resources to measure meteorological conditions. More observations in the coastal ocean are required to fully understand air-sea interactions over these land-deep sea transition regions, which further justifies the need for improved coastal ocean observing systems.

Acknowledgments. This work was supported by the Office of Naval Research (Grants N00014-98-1-0158 and N00014-02-1-0972). Special thanks are offered to the family of Elsie and William Knight for the fellowship endowment that helped to support J. I. Virmani.
Fieldwork and computer support was provided by Ocean Circulation Group members: R. Cole, J. Donovan, C. Merz, and P. Smith. Discussions with OCG members and S. Buehler, R. Helber, C. Holland, R. Fenner, S. Javonshire, D. Mayer, and T. Short proved helpful. The data for the cloud-free SST climatology image was provided by Y. Liu. Mooring work was conducted with the help of the crews of the R/V Suncoaster and R/V Bellows. NCEP reanalysis data were obtained from the NOAA-CIRES Climate Diagnostics Center, Boulder, Colorado (more information available online at http://www.cdc.noaa.gov), and C-MAN station data were obtained from the NOAA National Data Buoy Center. The authors thank the reviewers for their constructive comments.

\section{REFERENCES}

Breaker, L. C., D. B. Gilhousen, and L. D. Burroughs, 1998a: Preliminary results from long-term measurements of atmospheric moisture in the marine boundary layer in the Gulf of Mexico. J. Atmos. Oceanic Technol., 15, 661-676.

,,-- H. L. Tolman, and L. D. Burroughs, 1998b: Initial results from long-term measurements of atmospheric humidity and related parameters in the marine boundary layer at two locations in the Gulf of Mexico. J. Mar. Syst., 16, 199-217.

Buck, A. L., 1981: New equations for computing vapor pressure and enhancement factor. J. Appl. Meteor., 20, 1527-1532.

Cereceda, P., and R. Schemenauer, 1991: The occurrence of fog in Chile. J. Appl. Meteor., 30, 1097-1105.

Court, A., and R. D. Gerston, 1966: Fog frequency in the United States. Geogr. Rev., 56, 543-550.

Crescenti, G. H., R. E. Payne, and R. A. Weller, 1990: Improved Meteorological measurements from buoys and ships (IMET): Preliminary comparisons of humidity sensors. WHOI Tech. Rep. WHOI-90-18, 57 pp.

DiMego, G. J., L. F. Bosart, and G. W. Endersen, 1976: An examination of the frequency and mean conditions surrounding frontal incursions into the Gulf of Mexico and Caribbean Sea. Mon. Wea. Rev., 104, 709-718.

Elliott, W. P., and D. J. Gaffen, 1991: On the utility of radiosonde humidity archives for climate studies. Bull. Amer. Meteor. Soc., 72, 1507-1520.

Emmons, G., and R. B. Montgomery, 1947: Note on the physics of fog formation. J. Meteor., 4, 206-209.

Fairall, C. W., E. F. Bradley, D. P. Rogers, J. B. Edson, and G. S. Young, 1996: Bulk parameterization of air-sea fluxes for Tropical Ocean-Global Atmosphere Coupled-Ocean Atmosphere Response Experiment. J. Geophys. Res., 101, 3747 3764.

Fenner, R. L., 1973: Use of cellulose crystallite structures with solid state strain gages for humidity and moisture measurement. ISA Convention, ASI 73249, 251-252.

Fernandez-Partagas, J., and C. N. K. Mooers, 1975: A subsynoptic study of winter cold fronts in Florida. Mon. Wea. Rev., 103, 742-744.

Garand, L., C. Grassotti, J. Hallé, and G. L. Klein, 1992: On differences in radiosonde humidity-reporting practices and their implications for numerical weather prediction and remote sensing. Bull. Amer. Meteor. Soc., 73, 1417-1423. 
Gerber, H. E., 1981: Microstructure of a radiation fog. J. Atmos. Sci., 38, 454-458.

Gill, A. E., 1982: Atmosphere-Ocean Dynamics. Academic Press, $662 \mathrm{pp}$.

Golden, J. H., R. Serafin, V. Lally, and J. Facundo, 1986: Atmospheric sounding system. Mesoscale Meteorology and Forecasting, P. S. Ray, Ed., Amer. Meteor. Soc., 50-70.

Goodman, J., 1977: The microstructure of California coastal fog and stratus. J. Appl. Meteor., 16, 1056-1067.

He, R., and R. H. Weisberg, 2002: West Florida shelf circulation and temperature budget for the 1999 spring transition. Cont. Shelf Res., 22, 719-748.

—, and - 2003: West Florida shelf circulation and temperature budget for the 1998 fall transition. Cont. Shelf Res., 23, $777-800$.

Henry, W. K., 1979: Some aspects of the fate of cold fronts in the Gulf of Mexico. Mon. Wea. Rev., 107, 1078-1082.

Higgins, R. W., K. C. Mo, and S. D. Schubert, 1996: The moisture budget of the central United States in spring as evaluated in the NCEP/NCAR and the NASA/DAO reanalyses. Mon. Wea. Rev., 124, 939-963.

Hudson, J. G., 1980: Relationship between fog condensation nuclei and fog microstructure. J. Atmos. Sci., 37, 1854-1867.

Huh, O. K., W. J. Wiseman Jr., and L. J. Rouse Jr., 1978: Winter cycle of sea surface thermal patterns, northeastern Gulf of Mexico. J. Geophys. Res., 83, 4523-4529.

Kalnay, E., and Coauthors, 1996: The NCEP/NCAR 40-Year Reanalysis Project. Bull. Amer. Meteor. Soc., 77, 437-471.

Katsaros, K. B., and Coauthors, 1994: Measurements of humidity and temperature in the marine environment during the HEXOS main experiment. J. Atmos. Oceanic Technol., 11, 964-981.

Lala, G. G., E. Mandel, and J. E. Jiusto, 1975: A numerical evaluation of radiation fog variables. J. Atmos. Sci., 32, 720-728.

Leipper, D. F., 1994: Fog on the U.S. west coast: A review. Bull. Amer. Meteor. Soc., 75, 229-240.

Lewis, J., D. Koracin, R. Rabin, and J. Businger, 2003: Sea fog off the California coast: Viewed in the context of transient weather systems. J. Geophys. Res., 108, 4457, doi:10.1029/ 2002JD002833.

Liu, W. T., W. Tang, and P. P. Niiler, 1991: Humidity profiles over the ocean. J. Climate, 4, 1023-1034.

Meyer, M. B., J. E. Jiusto, and G. G. Lala, 1980: Measurements of visual range and radiation-fog (haze) microphysics. J. Atmos. Sci., 37, 622-629.

Muller, S. H., and P. J. Beekman, 1987: A test of commercial humidity sensors for use at automatic weather stations. $J$. Atmos. Oceanic Technol., 4, 731-735.

NCDC, 1998-2003: Storm Data. Vols. 40-45, Nos. 1-5, 11-12, 8310 pp.

Noonkester, V. R., 1979: Coastal marine fog in southern California. Mon. Wea. Rev., 107, 830-851.

Peace, R. L., Jr., 1969: Heavy-fog regions in the conterminous United States. Mon. Wea. Rev., 97, 116-123.

Peixoto, J. P., and A. H. Oort, 1996: The climatology of relative humidity in the atmosphere. J. Climate, 9, 3443-3463.

Pilié, R. J., E. J. Mack, C. W. Rogers, U. Katz, and W. C. Kocmond, 1979: The formation of marine fog and the development of fog-stratus systems along the California coast. $J$. Appl. Meteor., 18, 1275-1286.

Price, J. F., C. N. K. Mooers, and J. C. Van Leer, 1978: Observation and simulation of storm-induced mixed-layer deepening. J. Phys. Oceanogr., 8, 582-599.

Rasmusson, E. M., 1967: Atmospheric water vapor transport and the water balance of North America: Part I. Characteristics of the water vapor flux field. Mon. Wea. Rev., 95, 403-426.

Roach, W. T., 1995: Back to basics: Fog. Part 3-The formation and dissipation of sea fog. Weather, 50, 80-84.

Stone, R. G., 1936: Fog in the United States and adjacent regions. Geogr. Rev., 26, 111-134.

Telford, J. W., and S. K. Chai, 1993: Marine fog and its dissipation over warm water. J. Atmos. Sci., 50, 3336-3349.

Virmani, J. I., and R. H. Weisberg, 2003: Features of the observed annual ocean-atmosphere flux variability on the West Florida shelf. J. Climate, 16, 734-745.

Weisberg, R. H., B. D. Black, and H. Yang, 1996: Seasonal modulation of the West Florida continental shelf circulation. Geophys. Res. Lett., 23, 2247-2250.

Woodcock, A. H., 1978: Marine fog droplets and salt nuclei-Part I. J. Atmos. Sci., 35, 657-664.

- D. C. Blanchard, and J. E. Jiusto, 1981: Marine fog droplets and salt nuclei-Part II. J. Atmos. Sci., 38, 129-140.

Yang, H., and R. H. Weisberg, 1999: Response of the West Florida Shelf circulation to climatological wind stress forcing. J. Geophys. Res., 104, 5301-5320. 